\title{
A ACESSIBILIDADE DE IDOSOS E AS UNIDADES DE CONSERVAÇÃO: REFLEXÕES RUMO À DEMOCRATIZAÇÃO DOS ESPAÇOS PÚBLICOS DE LAZER
}

\author{
ACCESSIBILITY FOR ELDERLY PEOPLE AND CONSERVATION UNITS: REFLECTIONS \\ ON THE DEMOCRATIZATION OF PUBLIC LEISURE SPACES
}

\section{LA ACCESIBILIDAD PARA PERSONAS MAYORES Y LAS UNIDADES DE CONSERVACIÓN: REFLEXIONES RUMBO A LA DEMOCRATIZACIÓN DE LOS ESPACIOS PÚBLICOS DE OCIO}

Fabiane Imenes Luiz

Esp. em Gestão Ambiental (UFSCAR) Bacharel em Turismo e Meio Ambiente (UNESPAR) fabiane_imenes@hotmail.com Juliana Carolina Teixeira MSc. em Geografia (UEM) Bacharel em Turismo e Meio Ambiente (UNESPAR) Docente do curso de Turismo e Meio Ambiente (UNESPAR) julianatma@gmail.com Data de Submissão: 30/07/2015 Data de Aprovação: 01/12/2015

RESUMO: Frente ao processo de urbanização, a busca por atividades de lazer em áreas naturais é cada vez mais crescente. Um dos principais espaços utilizados para a prática desse segmento são os parques, que visam conservar o ambiente e proporcionar a visitação pública. Neles, as trilhas são um dos principais meios de acesso aos atrativos, devendo oferecer segurança e, quando autoguiadas, autonomia aos visitantes. Esse estudo avaliou as condições de acessibilidade para usuários idosos da trilha Peroba do Parque Estadual Lago Azul, em Campo Mourão (PR). Como procedimentos metodológicos, optou-se, em um primeiro momento, por uma pesquisa bibliográfica e documental. Posteriormente, desenvolveu-se um estudo de campo para levantar as competências dos condutores quanto à segurança de visitantes idosos e aos obstáculos enfrentados por esse grupo. Os resultados mostraram que as competências dos condutores atendem parcialmente às 
necessidades de segurança de visitantes idosos e que a trilha estudada apresenta obstáculos, que limitam a segurança e a autonomia desses indivíduos. As deficiências estruturais observadas resultam das deficiências relacionadas às políticas públicas na área e à responsabilidade do Estado sobre elas. Portanto, a promoção da acessibilidade em trilhas torna-se passo fundamental para que se possa garantir uma maior democratização desses espaços de lazer.

Palavras-chave: Idosos. Acessibilidade. Trilha.

ABSTRACT: Faced with the process of urbanization, the search for leisure activities in natural areas is increasingly. One of the main places used by this segment is parks, which aim to preserve the environment and enable visits by the public. Trails are one of the main means of access to the attractions. These should be safe, and when self-guided, and should enable visitors to use them independently. This study evaluates the conditions of accessibility for elderly users of the Peroba trail, in the Parque Estadual Lago Azul [Lago Azul State Park], Cain Campo Mourão (PR). The methodological procedures included a literature review and document research. Subsequently, we conducted a field study to identify the skills of park guides in relation to the safety of elderly visitors and the obstacles faced by this group. The results showed that the skills of the park guides partially meet the safety needs of the elderly visitors, and that the trail studied has some obstacles that limit safety and autonomy. The structural problems observed are the result of shorfalls in public policies in the area, and the responsibility of the state to deal with them. Therefore, promoting the accessibility of trails is a critical step to ensuring greater democratization of these leisure spaces.

Keywords: Elderly. Accessibility. Trail.

RESUMEN: Frente al proceso de urbanización, crece cada vez más la búsqueda de actividades de ocio en áreas naturales. Uno de los principales espacios utilizados para la práctica de ese segmento son los parques, cuyo objetivo es conservar el ambiente y proporcionar oportunidad para la visitación pública. En ellos, los senderos son uno de los principales medios de acceso a los atractivos y deben ofrecer seguridad y, cuando son autoguiadas, autonomía a los visitantes. Este estudio evaluó las condiciones de accesibilidad para usuarios mayores del sendero Peroba del Parque Estadual Lago Azul, en Campo Mourão (PR). Como procedimientos metodológicos, se optó en el primer momento por una investigación bibliográfica y documental. Posteriormente se desarrolló un estudio de campo para analizar las competencias de los conductores en relación a la seguridad de visitantes mayores y a los obstáculos enfrentados por ese grupo. Los resultados mostraron que las competencias de los conductores atienden parcialmente a las necesidades de seguridad de los visitantes mayores y que el sendero estudiado presenta obstáculos que limitan la seguridad y la autonomía de esos individuos. Las deficiencias estructurales observadas son el resultado de las deficiencias relacionadas a las políticas públicas en el área y a la responsabilidad del Estado sobre ellas. Por lo tanto, la promoción de la accesibilidad en senderos se vuelve un paso fundamental para que se pueda garantizar una mayor democratización de esos espacios de ocio.

Palabras clave: Adultos mayores. Accesibilidad. Sendero. 
$\mathrm{F}$ rente aos debates relacionados à questão ambiental, muito se discutiu quanto à sustentabilidade da atividade turística, a qual é promovida, também, em áreas naturais protegidas. Desenvolveu-se, assim, a ideia de um turismo alternativo, contrário ao turismo predatório, o qual não gerasse prejuízos às comunidades e ao meio ambiente (PIRES, 2002). Nesse contexto surgiu o ecoturismo, um dos segmentos mais difundidos mundialmente e que tem como um dos principais espaços para o seu desenvolvimento, os parques.

Dentre os grupos sociais que configuram a demanda por lazer e/ou recreação em parques, encontram-se grupos de idosos. Corazza (2001) destaca que a motivação de desfrutar do tempo livre faz com que muitos idosos optem por novas descobertas e por conhecer coisas e lugares diferentes. Dessa maneira, o turismo surge como meio de alcançar esses objetivos.

No entanto, em decorrência do processo de envelhecimento, os idosos enquadram-se no grupo de pessoas com mobilidade reduzida, o que significa dizer que apresentam redução da mobilidade, flexibilidade, coordenação motora e percepção. Assim sendo, a existência dessas especificidades devem ser observadas e avaliadas anteriormente ao exercício de qualquer atividade desenvolvida por esses indivíduos.

Ao considerar que, nos parques, as trilhas são um dos principais meios de acesso aos atrativos, elas devem ser projetadas de forma a garantir a conservação do espaço visitado e suprir as necessidades de lazer e/ou recreação de seus visitantes (ANDRADE, 2005). Desse modo, as trilhas devem estar aptas a atender às especificidades dos grupos de idosos e isso é possível a partir da promoção da acessibilidade.

Com base no exposto, surge a problemática do presente estudo: a trilha Peroba, localizada no Parque Estadual Lago Azul (PELA), em Campo Mourão $(P R)$, atende às necessidades de acessibilidade de usuários idosos? Assim, o objetivo desse estudo é, portanto, avaliar as condições de acessibilidade para usuários idosos da trilha Peroba do PELA. 
Quanto aos procedimentos metodológicos, optou-se, em um primeiro momento, pela pesquisa exploratória, bibliográfica e documental. A partir delas foi possível levantar dados prévios da trilha Peroba, referências bibliográficas referentes às temáticas do estudo e, ainda, documentos que apresentam orientações e normativas relacionadas à acessibilidade para pessoas com mobilidade reduzida em trilhas de Unidades de Conservação (UCs).

Posteriormente optou-se por um estudo de campo no PELA, onde foi possível desenvolver uma pesquisa qualitativa para avaliar as condições de acessibilidade da trilha Peroba. Como técnicas para a pesquisa de campo foi utilizada a de observação sistemática, que ocorreu juntamente à realização da trilha com um grupo de idosos; utilizou-se, ainda, da aplicação de questionário com os condutores do parque, objetivando identificar suas competências pessoais frente às necessidades de segurança de grupos de idosos.

O trabalho encontra-se dividido em cinco partes. A primeira delas trata da presente introdução. A segunda parte discorre sobre as UCs, a inclusão social de idosos nessas áreas e sobre as orientações e normativas existentes sobre a acessibilidade de pessoas com mobilidade reduzida em áreas naturais. A terceira parte trata da metodologia, sendo descritos os procedimentos tomados para a realização da pesquisa. A quarta parte apresenta os resultados da pesquisa, caracterizando o objeto de estudo. A quinta e última parte apresenta as considerações finais da presente pesquisa.

\section{AS UNIDADES DE CONSERVAÇÃO E AS ORIENTAÇÕES E NORMATIVAS DE ACESSIBILIDADE PARA PESSOAS COM MOBILIDADE REDUZIDA}

Historicamente, com diferentes objetivos relacionados aos recursos naturais, buscou-se a criação de áreas naturais protegidas, ou seja, "áreas de terra e/ou mar especialmente dedicadas à proteção e manutenção da diversidade biológica e de seus recursos naturais e culturais associados, manejadas por meio dos instrumentos legais e outros meios efetivos" (ROCKTAESCHEL, 2006, p.52). 
Brito (2000) explica que o marco fundamental da estratégia do estabelecimento do sistema de áreas naturais protegidas foi a criação do Parque Nacional de Yellowstone nos EUA, em 1872, ainda que em uma perspectiva urbanista e muito embora a definição do conceito de parque já fosse existente e que outras áreas protegidas já estivessem definidas anteriormente a essa data.

Entre 1959 e 1962, de acordo com Magnanini (2002), a ONU e a International Union for Conservation of Nature and Natural Resources (IUCN), trabalharam e editaram a Lista dos Parques Nacionais e Reservas Equivalentes, documento que classificava as áreas protegidas no planeta e que teve sua segunda edição em 1971, dando um panorama conservacionista que englobava cento e quarenta países.

No Brasil, no que tangem às ações em benefício à preservação e à conservação de suas áreas, destacaram-se as iniciativas de André Rebouças; o brasileiro, motivado pela experiência norte-americana, propunha, desde 1876, a criação de parques no país. Sua ideia se concretizou, parcialmente, em 1896, com a criação do Parque Estadual de São Paulo e, em 1937, com a criação do primeiro Parque Nacional Brasileiro, o de Itatiaia (MAGNANINI, 2002).

Contudo um dos grandes passos para a proteção das áreas naturais brasileiras foi a aprovação, em 2000, do Sistema Nacional de Unidades de Conservação (SNUC), sendo a primeira normatização nacional das áreas naturais protegidas por lei. A Lei n 9.985/2000 estabeleceu critérios e normas para a criação, implantação e gestão das UCs.

O SNUC é composto pelo conjunto de UCs Federais, Estaduais, Municipais e particulares, as quais se encontram distribuídas em doze categorias de manejo, sendo cada uma dessas diferenciadas de acordo com a forma de proteção e usos permitidos. Costa (2002) ressalta que as UCs podem ser vinculadas a diferentes órgãos administrativos, de acordo com a sua natureza, seu objetivo e seu estatuto. Contudo a maior parte das UCs está sob administração direta ou indireta do IBAMA, ou outros órgãos governamentais estaduais ou municipais competentes na área ambiental.

De acordo com Costa (2002, p.32), "o objetivo básico das UCs de uso sustentável é compatibilizar a conservação da natureza com o uso sustentável de parcela dos seus recursos naturais". Portanto são UCs de uso sustentável: 
Área de Proteção Ambiental; Área de Relevante Interesse Ecológico; Floresta Nacional; Reserva Extrativista; Reserva da Fauna; Reserva de Desenvolvimento Sustentável e Reserva Particular do Patrimônio Natural.

Já as UCs de proteção integral têm como o objetivo principal preservar a natureza, sendo admitido apenas o uso indireto dos seus recursos naturais, com exceção dos casos previstos em lei (COSTA, 2002). São UCs de uso integral: Estação Ecológica; Reserva Biológica; Parque Nacional; Monumento Natural e Refúgio da Vida Silvestre. Portanto, cada UC dispõe da permissão (sujeita às normas e restrições) ou proibição do uso dessas áreas para visitação pública.

Os parques são uma das categorias de UCs mais conhecidas mundialmente e isso se deve, principalmente, pelo fato deles unirem a conservação dos recursos naturais ao uso público para fins educacionais, recreativos e científicos. Costa (2002) explica que eles representam um grande atrativo turístico para o Brasil, sendo responsáveis pelo marketing do segmento do ecoturismo.

Em se tratando do breve levantamento histórico construído nessa pesquisa, compreende-se que o Brasil possui particularidades específicas que tangem sobre a conservação de seus recursos naturais e sobre a visitação dessas áreas. É preciso, portanto, refletir a realidade brasileira e a responsabilidade do Estado sobre suas áreas protegidas, sendo as pesquisas ferramentas importantes na construção de orientações e políticas que levem em consideração as realidades locais.

A visitação pública em parques está sujeita às normas e às restrições estabelecidas em seu Plano de Manejo, que se trata de um documento técnico, o qual, dentre outros pontos, também define os objetivos gerais da UC que determinam a gestão de suas áreas, inclusive aquelas abertas ao público em geral.

Ainda, a fim de proporcionar o ordenamento espacial das áreas dos parques, utiliza-se o zoneamento. Esse é responsável pela:

[...] definição de setores ou zonas em uma Unidade de Conservação com objetivos de manejo e normas específicas, com o propósito de proporcionar os meios e as condições para que todos os objetivos da unidade possam ser alcançados de forma harmônica e eficaz. (SNUC, $2000, s / p)$. 
Entre as áreas onde a visitação pública é permitida encontram-se as zonas denominadas de uso intensivo e uso extensivo. A zona de uso intensivo, de acordo com o SNUC (2000), é constituída por áreas naturais ou alteradas pelo homem, cujo objetivo do manejo é o de facilitar a recreação intensiva e a educação ambiental.

Já a zona de uso extensivo corresponde às áreas que proporcionam atividades educativas, interpretativas e recreativas - essas atividades, no entanto, devem ser de baixa intensidade no que se refere ao número de pessoas, à presença de infraestrutura e a outras facilidades, além do desenvolvimento de atividades científicas e monitoramento (SNUC, 2000).

As trilhas são um dos principais meios de acesso às áreas de uso público em parques. Andrade (2005) ressalta que é por meio delas que o visitante adquire contanto com a natureza, paisagens e lugares, favorecendo a criação de um sentimento de preservação pelo ambiente. Ainda, de acordo com o autor, um dos principais objetivos das trilhas de uso público em áreas naturais é suprir as necessidades recreativas dos visitantes, de maneira que o ambiente seja mantido estável e ofereça ao visitante segurança e conforto.

As trilhas podem ser guiadas, ou seja, realizadas com o acompanhamento de condutores; ou autoguiadas, quando os visitantes as trilham sozinhos, sem o auxílio de condutores. Quando autoguiadas, Andrade (2005) ressalta que a sinalização da trilha deve ser sistemática e compreensível, de forma que o visitante possa realizá-la de maneira segura.

A sinalização em trilhas pode se dar por meio de marcação à tinta, placas, montes de pedra (totem), fitas, entre outros. Uma das mais utilizadas são as placas, que de acordo com Andrade (2005), têm um papel muito importante, pois informam quanto ao nome, à direção, aos pontos importantes, à distância e ao destino da trilha.

O que se percebe, no entanto, de acordo com Andrade (2005), é uma carência acentuada em UCs no que se refere à real preocupação com as suas trilhas que, segundo o autor, configuram-se como equipamentos básicos de lazer e/ou recreação. Compreende-se que essa carência faz parte de um contexto maior de dificuldades enfrentadas em todos os parques brasileiros cuja infraestrutura é precária, em muitos casos, e os recursos humanos não se apresentam suficientes 
para gerir o uso público nas UC's brasileiras (DOUROJEANNI; PÁDUA, 2007).

Segundo Costa (2002), a oferta de infraestrutura mínima é condição essencial para o atendimento às necessidades da demanda turística. Considerando que a visitação em zonas de uso público de parques se dá a partir de diferentes públicos, as suas trilhas devem estar aptas a atender às especificidades desses grupos, tais como crianças, pessoas com deficiência, pessoas com mobilidade reduzida, entre outros; e é nesse contexto que surgem as discussões pertinentes à promoção de acessibilidade em trilhas.

Um dos grupos que está incluso na visitação dessas áreas são os idosos ${ }^{1}$. As atividades de lazer para idosos se diferem das atividades de lazer praticadas em outras fases da vida, não só pela mudança de hábitos e preferências como, também, pelas mudanças físicas decorrentes do envelhecimento.

O envelhecimento é um processo complexo que envolve muitas variáveis, dentre elas a genética, o estilo de vida e as doenças crônicas, as quais interagem e influenciam a maneira pela qual os indivíduos envelhecem (CORAZZA, 2001). Nesse caso, Parker (1978) argumenta que a idade é, sem dúvida, um fator que influencia as mudanças nos padrões e nas preferências quanto às atividades de lazer.

Corazza (2001) explica que, diante da motivação de desfrutar do tempo livre muitos idosos tornam-se verdadeiros aventureiros, optando por novas descobertas, por conhecer coisas e lugares que são, para eles, na maioria das vezes, completamente desconhecidos. Por essa razão, o turismo acaba sendo algo extremamente agradável e isso se dá não apenas pela oportunidade de conhecernovos lugares, mas, também, por poderem vivenciar novas experiências e conviver com outras pessoas.

O turismo, em uma sociedade que defende a equiparação de oportunidades para todos, precisa, no entanto, adequar-se às necessidades específicas dos indivíduos, a fim de que todos possam desfrutá-lo da melhor maneira possível (SASSAKI, 1997). No que se refere aos idosos, Parker (1978) explica que a saúde e a mobilidade têm importante efeito tanto na quantidade quanto na qualidade do lazer desse grupo.

1 Frente às diversas terminologias, para o presente trabalho optou-se pela utilização do termo idoso, uma vez que este é o adotado pelo direito brasileiro, a exemplo da Lei $n^{\circ} 10.741 / 2003$, que dispõe sobre o Estatuto do Idoso e que regula os direitos assegurados às pessoas com idade igual ou superior a sessenta anos. 
Melo (2003) argumenta que o idoso possui, assim como os demais, o direito e o dever de contribuir para a sociedade, de participar ativamente no traçar de seus rumos, não devendo ser menosprezado. O autor ressalta, ainda, que os programas de lazer devem estar atentos as tais dimensões, também contribuindo para potencializar a compreensão e a contribuição dos idosos.

Democratizar o lazer implica democratizar o espaço (MARCELLINO, 1983). Sassaki (1997) afirma que, para que se possam incluir todas as pessoas, a sociedade deve ser modificada a partir do pressuposto de que é ela quem precisa ser capaz de atender às necessidades de seus indivíduos.

A partir desse contexto surge o conceito de inclusão social, sendo:

[...] o processo pelo qual a sociedade se adapta para poder incluir, em seus sistemas sociais gerais, pessoas com necessidades especiais e, simultaneamente, estas se preparam para assumir seus papéis na sociedade. A inclusão social constitui, então, um processo bilateral no qual as pessoas, ainda excluídas, e a sociedade, buscam, em parceria, equacionar problemas, decidir sobre soluções e efetivar equiparação de oportunidades para todos. (SASSAKI, 1997, p.39-40).

O autor explica que a inclusão social é um processo que leva em consideração as transformações da mentalidade de todos os indivíduos - incluindo aqueles com as próprias necessidades específicas - e, também, dos ambientes físicos espaços internos e externos, equipamentos, aparelhos e utensílios, mobiliário e meios de transporte.

Ao se falar em inclusão social, porém, se faz necessário considerar que muitos indivíduos com necessidades específicas não têm acesso aos serviços, equipamentos e espaços turísticos devido as inexistentes e/ou insuficientes condições de acessibilidade. A Lein ${ }^{\circ}$ 10.098/2000, a qual estabelece normas gerais e critérios básicos para a promoção da acessibilidade das pessoas portadoras de deficiência ou com mobilidade reduzida, conceitua a acessibilidade como:

[...] possibilidade e condição de alcance para utilização, com segurança e autonomia, dos espaços, mobiliários e equipamentos urbanos, das edificações, dos transportes e dos sistemas e meios de comunicação, por pessoa portadora de deficiência ou com mobilidade reduzida. (BRASIL. Lei $\left.n^{\circ} 10.098,2000\right)$. 
A mesma lei, por efeito de classificação, considera a pessoa com mobilidade reduzida aquela que apresenta dificuldade de movimento, permanente ou temporariamente, o que gera uma redução da mobilidade, flexibilidade, coordenação motora e percepção. Nesse grupo encontram-se os obesos, as gestantes e os idosos.

Para que a acessibilidade seja concretizada, é necessário eliminar barreiras. Essas são definidas, de acordo com a Lei n 10.098/2000, como qualquer entrave ou obstáculo que limite ou impeça o acesso, a liberdade de movimento e a circulação com segurança dos indivíduos.

Para Sassaki (1997), segundo o paradigma da inclusão social, os sistemas de lazer e turismo devem adaptar-se às necessidades dos indivíduos. Quando consideradas as necessidades dos idosos, a acessibilidade em espaços de lazer torna-se um passo fundamental para que essa inclusão ocorra. Assim sendo, a eliminação de barreiras, relacionada à oferta de segurança e autonomia, permite que os idosos desfrutem do lazer tanto quanto os demais grupos da sociedade.

Acredita-se que é papel e responsabilidade do Estado a discussão e a formulação de políticas públicas que garantam a inclusão social dos diversos grupos sociais em áreas protegidas, bem como garantir a instrumentalização da qualidade do lazer e da experiência dos indivíduos nesses locais. Portanto, a fim de compreender como se dá a acessibilidade para idosos em áreas de uso público de UCs, buscou-se analisar algumas orientações e normativas que se relacionem com essa temática. Considerando que os idosos encontramse inseridos no grupo dos indivíduos com mobilidade reduzida, o presente estudo deu ênfase aos documentos que tratam, direta ou indiretamente, a acessibilidade para indivíduos com mobilidade reduzida em atividades de caminhada em trilhas, nosso principal objeto de estudo.

Para tanto, tornou-se pertinente uma discussão das orientações e normativas analisadas, uma vez que, embora relacionados com a temática da pesquisa, muitas delas não fornecem bases suficientes para o alcance do objetivo desse estudo. Dentre os documentos analisados estão aqueles elaborados, sobretudo, pelo Ministério do Turismo (MTUR), pelo Ministério do Meio Ambiente (MMA) e pela Associação Brasileira de Normas Técnicas (ABNT). 
O MTUR apresenta diversos documentos que fornecem orientações para a promoção da acessibilidade em espaços turísticos. Considerando que a caminhada em áreas naturais é uma atividade desenvolvida tanto pelo ecoturismo quanto pelo turismo de aventura, quatro deles foram analisados: Turismo e Acessibilidade - manual de orientações (2006); Turismo acessível bem atender no turismo de aventura adaptada (2009); Turismo de Aventura orientações básicas (2010); e Ecoturismo - orientações básicas (2010).

O manual de orientações intitulado "Turismo e Acessibilidade - manual de orientações", de 2006, apresenta termos e definições pertinentes à acessibilidade; orientações para bem atender aos turistas; orientações para a promoção da acessibilidade; além de expor as legislações e as normas técnicas existentes até o ano de sua publicação. No entanto, no que se refere às orientações para a promoção da acessibilidade, o documento se volta à promoção em transportes, à informação, à comunicação e em edificações de uso público e coletivo no espaço urbano; não fornece, porém, bases para a promoção em áreas naturais - sejam elas no espaço urbano ou não.

O documento intitulado "Turismo acessível - bem atender no turismo de aventura adaptado", de 2009, faz uma abordagem sobre os marcos legais e as bases do turismo de aventura; orientações para a adaptação de espaços e instalações; e do bem atender nas atividades de aventura. Ao tratar das orientações para a adaptação de espaços e instalações, o documento apresenta somente aquelas referentes aos espaços edificados, como hospedagem, restaurante, bilheterias, áreas comuns, entre outros. Ainda, apesar de considerar a caminhada como atividade de turismo de aventura, ele não fornece orientações para essa atividade, apenas para arvorismo, tirolesa, rapel, rafting, boia-cross e off road.

O manual "Turismo de Aventura - orientações básicas", de 2010, aborda o entendimento do segmento de turismo de aventura, as legislações turísticas, as normas e as legislações específicas e, principalmente, as bases para o desenvolvimento do segmento. Assim, o manual trabalha, especificamente, em prol da criação e da operação do produto turístico em si. Apesar de apresentar um tópico sobre segurança, ele não se propõe a discutir como ela pode ser alcançada. 
Por fim, o último documento do MTUR analisado foi o "Ecoturismo orientações básicas", de 2010, o qual apresenta o entendimento do segmento e as bases para o seu desenvolvimento. Ao trazer o tópico acessibilidade, o documento destaca que as áreas naturais que desenvolvem o ecoturismo devem ser adaptadas para a visitação de pessoas com mobilidade reduzida. No entanto, o tema não é amplamente discutido, dando apenas sugestões para a adaptação dessas áreas, como: rampas de acesso aos equipamentos, instalação de passarelas com corrimãos em trilhas, treinamento de monitores, fontes ampliadas, além da adaptação do centro de visitantes.

O MMA, em publicação do documento "Diretrizes para visitação em Unidades de conservação", em 2006, apresenta diretrizes para atividades realizadas por portadores de necessidades especiais; diretrizes para a segurança durante a visitação; e diretrizes para atividades específicas.

No que diz respeito às diretrizes para atividades realizadas por portadores de necessidades especiais, o documento aborda aquelas voltadas aos órgãos gestores de UCs. Uma dessas diretrizes é que órgãos gestores busquem organizações de pessoas portadoras de necessidades especiais durante a elaboração de padrões e as normas de acessibilidade, desenvolvendo atividades e produtos específicos para esse público. Ainda sugere que eles observem e atendam às legislações e às normas específicas. Entretanto o documento não especifica quais são essas legislações e normas a serem seguidas e adotadas.

Já em relação às diretrizes para a segurança, o documento sugere que os órgãos gestores identifiquem riscos à segurança e à saúde dos visitantes, colocando em prática normas, códigos, padrões e princípios vigentes. Porém ele não se propõe a expor quais são essas normas, códigos, padrões e princípios.

Por fim, as diretrizes para atividades específicas desenvolvidas em UCs se relacionam com aquelas voltadas às atividades de visitação mais frequentes nesses espaços; uma delas é a caminhada. Contudo, apesar de apresentar algumas recomendações de como essa atividade deve ser conduzida pelos órgãos gestores, o documento não trata da promoção da acessibilidade nos ambientes em que ela ocorre. 
Quanto às normas apresentadas pela $A B N T$, foram analisadas quatro delas: NBR 9050/2004 - "Acessibilidade a edificações, mobiliário, espaços e equipamentos urbanos"; NBR 15505-2/2007 - "Turismo com atividades de caminhada. Parte 2: Classificação de percursos"; NBR 15285/2005 - "Turismo de aventura - condutores - competência de pessoal"; e NBR 15505-1/2007 "Turismo com atividade de caminhada: Parte 1: Requisitos para o produto".

A NBR 9050/2004, referente à acessibilidade a edificações, mobiliário, espaços e equipamentos urbanos, de 2004, estabelece critérios e parâmetros técnicos a serem observados quando do projeto, construção, instalação e adaptação de edificações, mobiliário, espaços e equipamentos urbanos às condições de acessibilidade. Porém o documento não aborda aspectos referentes à acessibilidade em áreas naturais.

Já a NBR 15505-2, intitulada "Turismo com atividades de caminhada. Parte 2: Classificação de percursos", de 2007, trata das normas aplicáveis às caminhadas oferecidas como produto turístico. Porém ela expõe apenas os critérios para a classificação dos percursos, não apresentando normas específicas para a promoção da acessibilidade em trilhas.

A publicação da NBR 15285 - "Turismo de aventura - condutores competência de pessoal", de 2005, descreve as competências mínimas para condutores em atividades de turismo de aventura; conhecimentos; habilidades; atitudes ou atributos; manutenção e melhoria da competência; desenvolvimento de profissional contínuo; e manutenção da competência. A norma tornou-se pertinente ao presente estudo, uma vez que as competências pessoais dos condutores em UCs garantem a promoção da segurança destinada à visitação de grupos de idosos em trilhas.

Outra norma que se tornou pertinente foi a NBR 15505-1, intitulada "Turismo com atividade de caminhada: Parte 1: Requisitos para o produto", de 2007; ela trata das exigências quanto aos condutores, informações sobre o cliente, equipamentos, preparação dos clientes, informação ao cliente, exigência de segurança e gestão de riscos. Tal como as competências dos condutores, acredita-se que os critérios expostos por essa norma sejam essenciais para a garantia da segurança dos praticantes idosos da atividade de caminhada. 
Diante do exposto, observa-se que, apesar da existência de uma diversidade de materiais relacionados à acessibilidade, são poucos os que trazem orientações e normativas para a promoção da acessibilidade em áreas naturais. Isso evidencia a deficiência quanto às discussões relacionadas à inclusão social em áreas naturais, sobretudo em UCs, áreas que deveriam ser utilizadas pela população como meio de garantir a sua própria conservação.

Nesse sentido, dentre os documentos analisados, as NBRs 15285/2005 e 15505-1/2007 foram as que forneceram as melhores bases para a promoção da acessibilidade em trilhas. Embora elas não estejam diretamente relacionadas à temática, ambas tratam de requisitos que promovem a segurança durante a prática da caminhada.

\section{METODOLOGIA}

O levantamento da maior parte dos dados e a análise dos resultados se basearam em esforços no plano qualitativo. Segundo Richardson et al. (1985), a abordagem qualitativa de um problema justifica-se por ser uma forma adequada para se entender a natureza de um fenômeno social. Desse modo, a pesquisa qualitativa ocorreu a fim de avaliar as condições de acessibilidade para visitantes idosos da trilha Peroba.

Entretanto algumas técnicas quantitativas foram utilizadas para coleta de parte dos dados necessários ao trabalho. A demanda de idosos do PELA foi quantificada e foram aplicados questionários com os condutores do parque a fim de identificar sua qualificação frente ao atendimento das necessidades de grupos de idosos.

Quanto aos objetivos da pesquisa, realizou-se, primeiramente, uma pesquisa exploratória. Dessa maneira, as primeiras visitas ao PELA permitiram a obtenção de informações preliminares acerca da realidade do objeto de estudo, cuja observação informal possibilitou a identificação de obstáculos frente à visitação de grupos de idosos na trilha Peroba.

Buscando-se a obtenção de um referencial teórico, desenvolveu-se uma pesquisa bibliográfica e documental. Para a pesquisa bibliográfica, foram utilizados 
livros, artigos científicos, monografias, teses, entre outros relacionados ao lazer, ecoturismo, áreas naturais protegidas, idosos, acessibilidade e inclusão social.

Para essa pesquisa, portanto, foram utilizados documentos de fontes primárias e oficiais, os quais foram obtidos em formatos de arquivos on-line. O resultado dessa pesquisa pôde ser observado no tópico: "As unidades de conservação e as orientações e normativas de acessibilidade para pessoas com mobilidade reduzida". A análise desses documentos possibilitou a adoção das NBRs 15285/2005 - "Turismo de Aventura - Condutores - Competências de pessoal" - e 15505-1/2007 - "Turismo com atividades de caminhada - Parte 1: Requisitos para produto" - como referenciais normativos para a pesquisa.

Posteriormente se desenvolveu um estudo de campo. Em um primeiro momento levantou-se o número de idosos que frequentaram o parque a partir de 2005 (ano de instituição do Plano de Manejo) até 2012 (em que os dados são completos do início ao fim do ano) em uma tentativa de levantar a demanda desse grupo pelas atividades no PELA. Isso foi possível a partir do acesso às fichas de cadastro de visitantes, o qual possibilitou o levantamento total de visitantes do parque e posterior contagem dos indivíduos acima dos sessenta anos de idade.

Ao receber determinados grupos, a trilha Peroba, embora seja autoguiada, é percorrida com a presença de ao menos um condutor do parque. Isso ocorre com grupos de crianças, idosos e quando um visitante e/ou outro grupo distinto solicitar o acompanhamento. O parque adota essa postura a fim de garantir a organização da visitação grupal e como forma de oferecer segurança aos grupos mais vulneráveis a acidentes ao longo do percurso.

Desse modo, sabendo que os grupos de idosos são acompanhados por condutores, buscaram-se identificar as competências desses frente ao atendimento das necessidades inerentes aos idosos. Para alcançar esse objetivo, foi elaborado questionário a ser aplicado com os três condutores.

Tratou-se de um questionário elaborado a partir das duas normativas da ABNT; as perguntas foram de múltipla escolha, que de acordo com Marconi e Lakatos (1996), embora sejam fechadas, apresentam uma série possíveis de respostas. Entretanto se acrescentaram campos de observações, caso o condutor sentisse a necessidade de adicionar alguma outra informação. 
Para a identificação de barreiras existentes na trilha Peroba, as quais, também, limitam a segurança e a autonomia de grupos de idosos, fez-se necessário o uso da técnica de observação sistemática. A observação sistemática ocorreu simultaneamente a uma trilha guiada com grupos de idosos que realizaram a trilha Peroba durante o mês de Setembro de 2013. Buscou-se identificar os obstáculos enfrentados por este grupo ao longo da trilha, tais como obstáculos físicos presentes no percurso, além da sinalização existente.

Marconi e Lakatos (1996) explicam que, para a observação sistemática, vários instrumentos podem ser utilizados, como: quadros, anotações, escalas, dispositivos mecânicos. Para a pesquisa, optou-se pela utilização de anotações. Contudo essas anotações foram sistematizadas de modo a contemplar, também, alguns aspectos observáveis nas NBRs utilizadas para a elaboração do questionário. Por fim, os resultados da pesquisa qualitativa, que correspondem aos dados obtidos por meio da pesquisa de campo, foram interpretados de forma a identificar se a trilha Peroba atende às necessidades de acessibilidade de grupos de idosos.

\section{A ACESSIBILIDADE PARA IDOSOS NO PARQUE ESTADUAL LAGO AZUL: UM OLHAR SOBRE A TRILHA PEROBA}

O PELA está localizado no Terceiro Planalto Paranaense, tendo seu centro geográfico nas coordenadas $24^{\circ} 05^{\prime} 16,98^{\prime \prime}$ a $24^{\circ} 13^{\prime} 59,58^{\prime \prime}$ de Latitude Sul e $52^{\circ}$ $17^{\prime} 48,85^{\prime \prime}$ a $52^{\circ} 21^{\prime} 22,36^{\prime \prime}$ Longitude Oeste, nos municípios de Campo Mourão e Luiziana (Figura 1). 
Figura 01: Localização do Parque Estadual Lago Azul

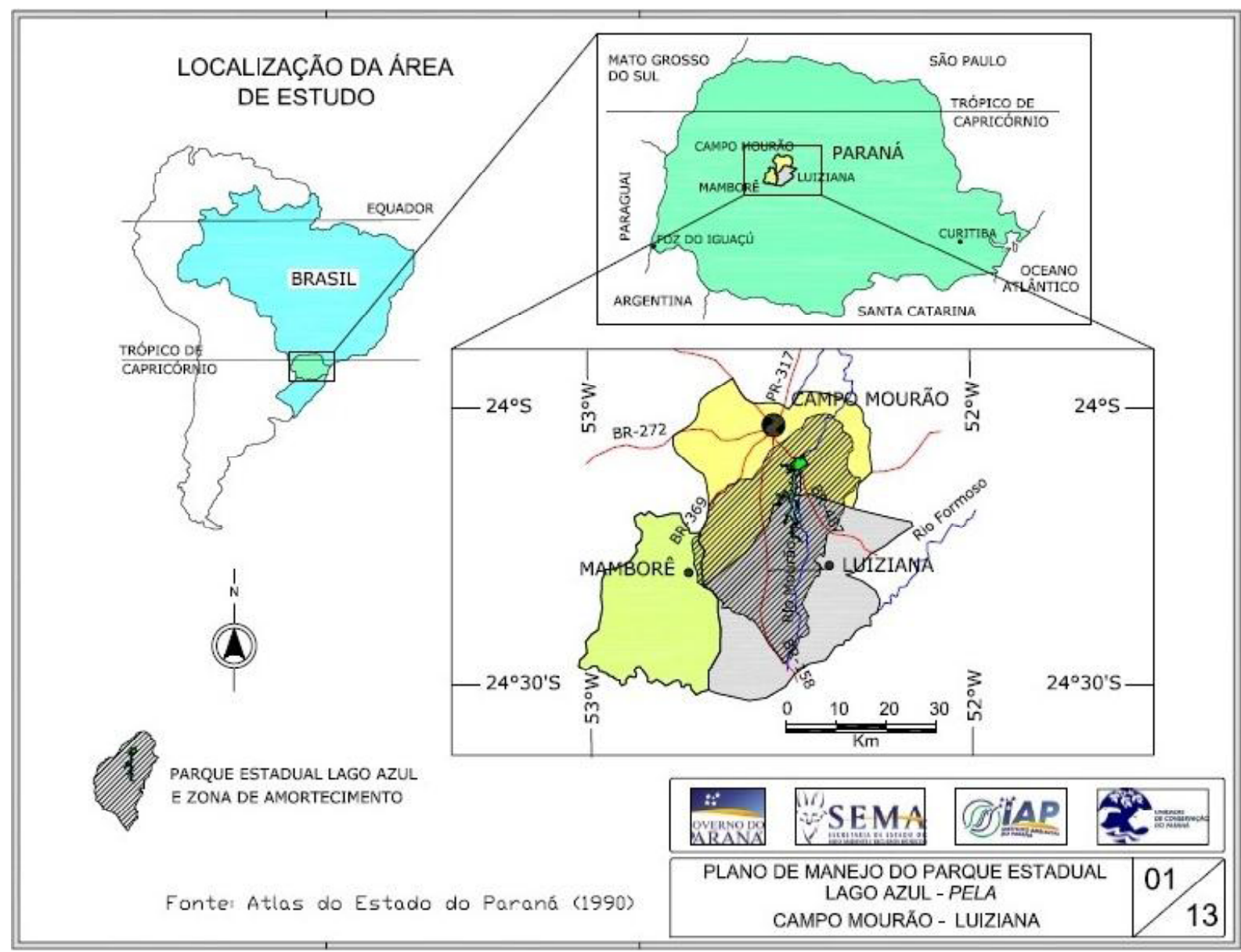

Fonte: Instituto Ambiental do Paraná (IAP), 2005.

O horário de funcionamento do parque é das $8 \mathrm{~h}$ às $17 \mathrm{~h}$, de terças as sextasfeiras, e das $14 \mathrm{~h}$ às $17 \mathrm{~h}$ aos sábados e aos domingos. Às segundas-feiras o parque é fechado para a visitação pública em função das atividades internas de manutenção e administração geral.

Quanto aos recursos humanos, o parque possui um gerente, quatro guardaparques, três estagiários, uma funcionária de serviços-gerais, cinco funcionários de manutenção, além de eventuais voluntários.

As áreas de uso público do parque encontram-se inseridas na zona de uso intensivo e zona de uso extensivo. A zona de uso intensivo compreende as áreas onde se encontram o Centro de Educação Ambiental (CEA), o estacionamento, a recepção, a área de lazer, as estruturas de apoio ao visitante e a edificação destinada ao museu natural. 
Já a zona de uso extensivo se subdivide em duas: Zona de Uso Extensivo 1, a qual compreende as áreas de trilhas interpretativas (Aventura e Peroba), os aceiros e as estradas internas do parque; e Zona de Uso Extensivo 2, a qual compreende o espelho d'água do reservatório e a área que vai do limite da faixa de segurança da barragem até o início do Paliteiro nas proximidades do sítio Scrovowski.

As trilhas Aventura e Peroba configuram-se como as áreas mais procuradas pelos visitantes da UC; é a partir delas que os visitantes têm a oportunidade de conhecer os principais atrativos do parque. É desejável que os visitantes agendem as trilhas previamente, mas o não agendamento não impede que elas sejam realizadas. É necessário que, antes da realização de ambas, o visitante siga até o CEA para preencher o cadastro de visitantes e receba algumas informações prévias quanto à realização da trilha desejada.

A trilha Aventura possui 3.500 metros de extensão e dá acesso às cachoeiras Salto Belo, Salto São João e ruínas da Usina São João. Para a realização dessa trilha é necessário ter mais de 14 anos, uma vez que, como o próprio nome da trilha sugere, ela possui obstáculos físicos que lhe dão características inerentes a uma caminhada de aventura. Ocorrem duas saídas diárias para essa trilha, sendo uma no período da manhã e uma no período da tarde. Por se tratar de uma trilha guiada, é necessário ter um ou mais condutores do parque acompanhando o(s) grupo(s) de visitantes.

Já a trilha Peroba possui 3.850 metros de extensão e dá acesso a uma cascata e ao lago interno. Essa trilha não possui restrição quanto à idade de seus visitantes e é autoguiada, ou seja, não é necessária a presença de condutores para a sua realização. A trilha Peroba trata-se de uma trilha circular, ou seja, é possível voltar ao ponto de partida sem repetir o percurso ou cruzar outros visitantes. A saída para essa trilha deve respeitar o limite máximo das 15h, uma vez que as atividades do parque encerram-se às $17 \mathrm{~h}$. É importante ressaltar que a presente pesquisa voltou-se à análise das condições de acessibilidade para usuários idosos nessa trilha em específico, uma vez que, por ser autoguiada e aberta ao público em geral, pressupõem-se que ela esteja apta a receber qualquer indivíduo. 
O início da trilha está localizado ao lado da sede do parque. Desse ponto até a primeira área de descanso são, aproximadamente, $2 \mathrm{~km}$ de extensão. Chegando ao ponto de descanso, os visitantes seguem, então, até a cascata. A partir da cascata é possível seguir até o lago existente no parque e retornar à sede por meio de uma estrada de terra. O percurso todo é percorrido, aproximadamente, em uma hora. No entanto, muitos visitantes, ao chegarem ao lago, utilizam-no como ponto de descanso antes de retornar à sede do parque. Assim, o gestor do parque calcula um tempo total de duas horas para a sua realização.

Durante os anos de 2005 a 2012 o PELA recebeu 23.874 visitantes, dos quais 270 estavam acima dos sessenta anos de idade; esse número de idosos corresponde a $1,13 \%$ do total de visitantes do parque. Embora esse levantamento aponte para uma quantidade pouco representativa de visitantes idosos, acredita-se que a demanda existente, por si só, explique a importância do parque se atentar para as especificidades desse grupo, cumprindo com os objetivos da UC e democratizando a sua visitação.

Para a realização da trilha Peroba com grupos de idosos, o parque disponibiliza condutores como forma de garantir uma maior segurança a esses indivíduos. Assim, a aplicação de questionários com os três condutores do parque possibilitou a identificação das competências desses frente ao atendimento das necessidades de segurança desses grupos. O questionário foi dividido em cinco partes, a saber: 1) Quantidade de condutores, auxiliares e visitantes por grupos; 2) Desenvolvimento profissional; 3) Informações sobre o visitante; 4) Equipamentos utilizados; e 5) Competências dos condutores.

A primeira parte do questionário buscou identificar a quantidade de condutores, auxiliares e visitantes por grupo. A NBR 15505-1 (2007) - referente aos requisitos para o turismo com atividades de caminhada - recomenda a existência de uma quantidade mínima de condutores e auxiliares por grupo. Assim, grupos de até 10 indivíduos precisam ser acompanhados por no mínimo 01 condutor e 01 auxiliar. Já os grupos de 11 a 20 indivíduos precisam de no mínimo 02 condutores e 01 auxiliar.

Os três condutores do PELA, quando questionados, responderam que, em grupos de até dez participantes, há um condutor e um auxiliar. Porém, em grupos de onze a vinte participantes, há apenas um condutor e um auxiliar. 
No caso de grupos acima de vinte indivíduos, mantém-se a quantidade de um condutor e um auxiliar.

Conforme a NBR 15285 (2005), referente às competências pessoais de condutores, o desenvolvimento profissional contínuo é essencial para a manutenção e a melhoria das competências dos condutores; ele pode ser alcançado por meio de experiência profissional adicional; estudo privado; treinamento orientado; participação em reuniões, palestras, seminários, conferências ou outras atividades pertinentes.

Quando questionados, todos os condutores responderam que participam de reuniões, palestras, seminários, conferências e outras atividades pertinentes. No entanto, a maioria é ofertada pelo meio acadêmico, e não pelo órgão gestor (IAP); isso porque os três condutores do PELA são universitários em período de estágio no parque, não sendo guias credenciados por órgão competente. Ainda, dois condutores afirmaram ter curso de recreação e aventura, e um deles afirmou ter experiência profissional adicional. Assim sendo, observa-se a carência, por parte do órgão responsável pela UC, em capacitar os seus condutores.

A NBR 15505-1 (2007) recomenda que a instituição que oferece atividade de caminhada encoraje o visitante a fornecer as informações de forma detalhada, facilitando o atendimento em caso de possíveis emergências. Dentre essas informações estão: nome; telefone para contato; número do documento; contato para caso de emergência; condições de saúde ou médicas específicas (como cirurgias; diabetes; problemas cardiovasculares, articulares, ósseos, respiratórios; fobias; gravidez); medicamentos em uso; idade; e experiência anterior com a atividade.

Os condutores afirmaram que o PELA apresenta um ficha de cadastro de seus visitantes, a qual exige informações quanto ao: nome; telefone; contato para caso de emergência; idade; meio de acesso; endereço; opção de trilha; e como o visitante tomou conhecimento do parque.

Nesse tópico, julga-se importante coletar dados referentes, especialmente, à condição de saúde dos visitantes, sobretudo dos idosos, que em função do processo deenvelhecimento podemapresentar problemas desaúdequedificultem o seu acesso à trilha (como os problemas respiratórios, cardiovasculares, cirurgias, 
etc.); informações quanto aos medicamentos em uso e experiência anterior com a atividade tornam-se, também, pertinentes, garantindo uma melhor segurança dos idosos e melhor adaptação da atividade desenvolvida.

A NBR 15505-1 (2007) recomenda que a operação do produto, nesse caso, a caminhada, deve assegurar que todos os condutores e auxiliares possuam todos os equipamentos necessários para a prática da atividade. São exemplos mínimos de equipamentos: estojo de primeiros-socorros; veículo de apoio; meio de comunicação que permita a comunicação entre condutores, auxiliares e veículo de apoio (ex: radiocomunicador, celular); sinais sonoros (ex: apito); canivete; relógio.

Quanto aos equipamentos utilizados pelos condutores ao longo da trilha, os três afirmaram utilizar veículo de apoio - que consiste em um automóvel do IAP, utilizado para a atividade de ronda pelos guardas-parques - e relógio; dois deles afirmaram utilizar canivete em caso de pequenos galhos na trilha.

Um condutor afirmou que há estojo de primeiros-socorros na UC, mas ele não é levado para a trilha. Acredita-se que é de extrema importância a utilização de um estojo de primeiros-socorros que possibilite o pronto-atendimento por um condutor, principalmente durante o acompanhamento de grupos de idosos. $\mathrm{O}$ mesmo condutor afirmou, ainda, que há, no parque, apito para a comunicação entre condutores, auxiliares e os próprios visitantes, porém ele não é utilizado.

Outro condutor acrescentou ao questionário que há, no PELA, radiocomunicadores, no entanto, eles são de uso dos guardas-parques e no momento não estão em funcionamento. Acredita-se que esse equipamento seja essencial para uso dos condutores, uma vez que facilita a comunicação entre condutores, auxiliares e veículo de apoio em caso de acidentes durante o percurso. Por fim, o questionário abordou as competências pessoais dos condutores, baseado em recomendações das duas NBRs. A fim de tornar o questionário o mais objetivo possível, dividiram-se as competências em dois grupos: o primeiro se relaciona às competências dos condutores frente ao atendimento aos grupos; e o segundo baseou-se nas competências relacionadas à segurança dos visitantes na trilha. 
No que diz respeito ao atendimento aos grupos de visitantes do PELA, buscou-se identificar as competências dos condutores frente ao atendimento das necessidades de seus visitantes ${ }^{2}$, tais quais: fornecer informações quanto a sua qualificação; cuidados com a segurança; atividade a ser realizada; vestuário adequado; ser capaz de adequar programas; ter conhecimento prévio das condições da trilha, entre outras.

Os três condutores afirmaram possuir quase todas as competências identificadas, porém nenhum deles afirmou ser capaz de instruir os visitantes quanto aos procedimentos de emergência aplicáveis (ex: como proceder em caso de incêndio, acidentes com animais peçonhentos, desmaios, etc.). Nesse caso, acredita-se que, tratando-se de grupo de idosos, instruções quanto aos procedimentos de emergência sejam pertinentes, mantendo o grupo informado e seguro quanto às ações que devem ser tomadas.

No grupo das competências relacionadas à segurança, buscaram-se identificar as competências inerentes à promoção da segurança aos visitantes durante a atividade de caminhada na trilha, tais quais: fazer análise das situações e cancelar a atividade em função de perigos e riscos; decidir sobre rotas alternativas; avaliar fatores que contribuam para acidentes (como quedas, um visitante se perder, acidentes com animais peçonhentos); observar sinais de desgaste físico e emocional dos visitantes; providenciar recursos ou suporte; dominar técnicas de primeiros-socorros, entre outras.

Dentre as competências levantadas, apenas um condutor afirmou ter condições de avaliar fatores que contribuam para acidentes, como quando um cliente se perder do grupo e/ou no caso de acidentes com animais peçonhentos. O mesmo acrescentou que, em caso de um visitante se perder, o guarda-parque poderá ser informado para proceder com a busca. Já em caso de acidentes com animais peçonhentos, um condutor explicou que, enquanto um condutor permanece na trilha com o grupo, o auxiliar retorna à sede do parque para acionar o atendimento médico. Dois condutores afirmaram possuir a competência de agir em caso de o visitante sentir labirintite, vertigem, entre outros.

2 Para acessar todas as competências consultar as NBRs 15285 (2005) e 15505-1 (2007) da Associação Brasileira de Normas Técnicas (ABNT). 
Diante das possíveis ocorrências, ressalta-se, novamente, a importância de um meio de comunicação entre condutores, auxiliares, veículos de apoio e a própria sede do parque; o uso de um radiocomunicador, por exemplo, agilizaria o acionamento de resgate médico, sem a necessidade de um auxiliar retornar à trilha ou percorrer trilhas alternativas (também chamadas trilhas de escapes, as quais são utilizadas pelos funcionários do parque em caso de emergências).

Os resultados decorrentes da aplicação de questionários com os condutores do parque apontaram, assim, que o acompanhamento de condutores, por si só, não representou uma oferta total de segurança para grupos de idosos. Frente às situações de riscos, os condutores mostram-se limitados quanto ao domínio de técnicas de primeiros-socorros, às informações aos visitantes e ao uso de equipamentos.

Nesse sentido, ressalta-se a importância das normativas técnicas analisadas nesse estudo que, aliadas ao treinamento e à qualificação dos condutores, podem oferecer uma visitação mais acessível e segura a esses grupos.

Além da análise das normativas, observando também a qualificação dos condutores com base nessas normativas, um grupo de 15 idosos foi analisado ao percorrer a trilha Peroba do Parque, observando-se a acessibilidade desses sujeitos no PELA. A fim de uma apresentação mais clara dos resultados, dividiuse a observação em quatro etapas, a saber: 1 ) Chegada do grupo ao parque; 2 ) Percurso correspondente ao início da trilha até a área de descanso; 3) Percurso correspondente à área de descanso até o lago; e 4) Percurso correspondente ao lago até a sede do parque.

Durante a chegada do grupo ao parque, observaram-se: a) informações solicitadas ao grupo; b) informações dadas ao grupo; c) quantidade de condutores e auxiliares que acompanhariam o grupo na trilha; e d) equipamentos que seriam levados junto aos condutores e aos auxiliares durante a trilha. Na segunda etapa foram observados: a) obstáculos físicos na trilha; b) sinais de desgaste físico e/ ou emocional dos indivíduos do grupo; e c) sinalização do percurso. Na terceira etapa: a) obstáculos físicos presentes na trilha; b) sinais de desgaste físico e/ ou emocional dos indivíduos do grupo; c) segurança ao atravessar a cascata; e d) sinalização do percurso. E na última etapa: a) sinais de desgaste físico e/ou emocional dos indivíduos do grupo; e b) sinalização do percurso. 
Ao analisar as quatro etapas foi possível levantar que, no momento da recepção dos indivíduos, todos foram encaminhados ao CEA onde eles preenchem a ficha de cadastro. A ficha contemplou apenas nome, cidade e idade dos visitantes. Como já mencionado, a NBR 15505-1 (2007) recomenda que as instituições encorajem os visitantes a fornecer informações detalhadas, de forma a facilitar o atendimento em caso de possíveis emergências. Assim, a ficha de cadastro de visitantes deveria contemplar, também, condições de saúde dos indivíduos, bem como medicamentos em uso e experiência anterior com a atividade a ser realizada.

Após o preenchimento das fichas, encaminharam os grupos para o auditório do CEA, onde um condutor e um auxiliar se apresentaram, dizendo nome e função, e apresentaram o vídeo institucional do órgão responsável pela UC (IAP). O vídeo contempla informações de fauna e flora, além de atitudes que os visitantes devem ter em UCs. Em seguida alguns cuidados com a segurança são assinalados, como: ao avistar um animal peçonhento, deixe-o passar; procure caminhar junto ao grupo; procure não tocar em plantas e árvores, pois podem ser tóxicas, além de nelas estar presente algum animal peçonhento. Trata-se sobre a trilha fornecendo dados referentes à extensão, ao tempo de caminhada e aos atrativos. Posteriormente o grupo foi encaminhado para a área externa, onde se iniciou um breve alongamento.

Independentemente da quantidade de participantes, os grupos sempre são guiados por dois condutores. Segundo as normas da NBR 15285 (2005), em grupos de onze a vinte visitantes, deve haver dois condutores e um auxiliar. Nesse caso, havia apenas dois para um total de 42 pessoas, pois, junto aos 15 idosos, havia mais 27 pessoas.

Como equipamentos para a trilha, o condutor e o auxiliar levaram apenas relógio, a fim de controlar o tempo do percurso. De acordo com a NBR 15505-1 (2007), os equipamentos úteis para a segurança na trilha, além de relógio, são: meio de comunicação, sinais sonoros e canivete. Ainda, a norma trata o veículo de apoio como um equipamento; esse estava disponível em caso de acidentes e possíveis emergências. 
Dentre os principais obstáculos físicos, foram identificados: raízes de árvores expostas, que geraram tombos; terreno íngreme, que diminuiu o ritmo da caminhada e gerou cansaço e sede nos indivíduos; terreno escorregadio, decorrente de pedras, no acesso à cascata; e troncos de árvores caídos e cipós pendentes, os quais exigiram uma maior atenção e esforço físico dos idosos ao atravessar esses obstáculos.

No que diz respeito à sinalização, supondo que a trilha Peroba seja uma trilha autoguiada, ela deve ser sistematizada e compreensível, de forma que o indivíduo seja capaz de percorrer a trilha de maneira autônoma e segura. No entanto, a observação identificou, principalmente, que as placas presentes no percurso não estão em bom estado de conservação, com informações apagadas ou desgastas.

Por fim, algumas respostas adquiridas por meio do questionário foram confirmadas, também, a partir da observação, como: número inadequado de condutores e auxiliares por quantidade de visitantes; solicitação limitada de informações dos visitantes; e ausência, na trilha, de equipamentos úteis em caso de acidentes e emergências.

Observou-se, por fim, que as dificuldades enfrentadas durante o percurso percorrido pelo grupo de idosos estão estreitamente ligadas às dificuldades vividas pelos parques brasileiros no manejo de seu uso público. Isso porque a existência de instruções e normativas não são unicamente suficientes para garantir a qualidade da experiência nessas áreas. Portanto é evidente que políticas públicas que tratem do manejo da visitação pública para tais indivíduos se fazem urgente.

\section{CONSIDERAÇÕES FINAIS}

Considerando que a acessibilidade encontra-se diretamente relacionada à inexistência de obstáculos, à promoção de segurança e à autonomia aos indivíduos, os resultados da pesquisa confirmaram, parcialmente, as duas hipóteses desse estudo. A trilha possui limitações quanto à segurança e à autonomia de idosos. É preciso investir na capacitação dos recursos humanos e na manutenção da trilha, bem como em melhorias e readequações quanto 
à sinalização; à implantação de pontos de apoio ao visitante; à estrutura da própria trilha, entre outros.

A adoção das normas bases dessa pesquisa, as quais se relacionam com segurança da atividade de caminhada, mostram-se, quando adotadas, como uma alternativa para tornar a atividade mais segura e acessível. No que tange, portanto, à avaliação das normativas, observa-se que existe possibilidade em adaptar as normativas para a implementação em áreas de uso público nas UCs, que podem nortear o trabalho a ser desenvolvido. É preciso, contudo, levantar normativa específica, corrigindo falhas das já existentes e levantando normativas que sejam compatibilizadas com as UCs.

Todavia, ao se pensar em adaptações em trilhas de UCs, deve-se considerar que elas dependem, diretamente, do plano de manejo da área, uma vez que ele será o responsável por fixar, em lei, os objetivos gerais da UC, as normas referentes ao uso da área, bem como toda a sua estrutura. Importante ressaltar que o plano de manejo do PELA não é atualizado há trezes anos e há carência na contratação de mais funcionários no quadro fixo, refletindo a falta de implantação de estruturas que atendam às necessidades de seus visitantes.

Como exposto no decorrer dessa pesquisa, o objetivo das UCs de uso integral no Brasil é permitir o uso indireto dos recursos naturais. Nessa categoria enquadramse os parques que possuem como objetivo central a conservação da natureza e também o manejo da visitação pública. Nesses parques observou-se também que as trilhas são ferramentas fundamentais para proporcionar aos visitantes experiências de contato com o ambiente natural e que ofereçam a interpretação e resultem na construção da sensibilização ambiental, entre outros objetivos.

Como asseverou Costa (2002), foi possível compreender que tais áreas devem oferecer aos seus visitantes estrutura mínima como fator básico para atender ás demandas do público que as visita de maneira geral. Dentre esses grupos, apontam-se, então, os idosos, que de maneira crescente buscam novas atividades, dentre elas, aquelas praticadas em meio natural. Compreendeuse que tal grupo social necessita de atenção especial no que tange à sua acessibilidade em ambientes naturais, pois como afirmou Marcellino (1983), democratizar o lazer significa democratizar também os espaços. 
Durante as análises realizadas, com os resultados coletados posteriormente ao levantamento da literatura e dos dados em campo, foi possível observar que a responsabilidade do Estado em assegurar a qualidade no uso público das UCs está aquém das necessidades dos diferentes grupos sociais, especialmente dos idosos, analisados nessa pesquisa. Por muitas razões não se cumpre com tal responsabilidade, uma vez que essas áreas se encontram com Planos de Manejo defasados, número de recursos humanos inadequado, infraestrutura precária, entre outros. Pois, a exemplo, no que diz respeito às trilhas nessas áreas, bem como apontou Andrade (2005), elas sofrem com a carência dos parques na preocupação da qualidade das mesmas e na experiência que elas podem atribuir aos seus visitantes.

É importante ressaltar que os resultados da pesquisa apontam não só para uma realidade particular como, também, brasileira. Nesse sentido, a existência de instruções e normativas não se fazem suficientes para atribuir uma experiência de qualidade aos grupos sociais em ambientes naturais protegidos. Isso porque se faz necessária a implementação de políticas públicas consistentes para o setor, que coloquem a responsabilidade dos envolvidos na esteira dessas discussões, pensando na particularidade e na realidade de cada local. Espera-se, portanto, que os resultados dessa pesquisa possam promover um maior debate quanto à temática acerca da acessibilidade em trilhas. Ainda, acredita-se que os resultados e as sugestões presentes nesse estudo possam, futuramente, ser repensados, e até mesmo aplicados, no PELA e em qualquer outro parque do Brasil.

\section{REFERÊNCIAS}

ASSOCIAÇÃO BRASILEIRA DE NORMAS TÉCNICAS. NBR 9050: Acessibilidade e edificações, mobiliário, espaços e equipamentos urbanos. 2. ed. Rio de Janeiro, 30 jun. 2004.

ASSOCIAÇÃO BRASILEIRA DE NORMAS TÉCNICAS. NBR 15505-1: Turismo com atividades de caminhada - Parte 1: Requisitos para o produto. 1. ed. Rio de Janeiro, 18 fev. 2008.

ASSOCIAÇÃO BRASILEIRA DE NORMAS TÉCNICAS. NBR 15505-2: Turismo com atividade de caminhada - Parte 2: Classificação de percursos. 1. ed. Rio de Janeiro, 18 mar. 2008.

ASSOCIAÇÃO BRASILEIRA DE NORMAS TÉCNICAS. NBR 15285: Turismo de aventura Condutores - Competência de pessoal. 1. ed. Rio de Janeiro, 31 nov. 2005. 
ISSN: 1983-7151

ANDRADE, Waldir Joel de. Manejo de trilhas para o ecoturismo. In: Ecoturismo no Brasil. Rita Mendonça, Zysman Neiman (Org.). Barueri, SP: Manole, 2005.

BRASIL. Diretrizes para visitação em Unidades de Conservação. Brasília: MMA, 2006.

BRASIL. Ecoturismo: orientações básicas. 2. ed. Brasília: MTUR, 2010.

BRASIL. Turismo acessível: bem atender no turismo de aventura adaptada. Vol. IV. Brasília: MTUR, 2009.

BRASIL. Turismo de aventura: orientações básicas. 3. ed. Brasília: MTUR, 2010.

BRASIL. Turismo e acessibilidade: manual de orientações. 2. ed. Brasília: MTUR, 2006.

BRASIL. Lei $n^{\circ}$ 10.098, de 19 de dezembro de 2000. Estabelece normas gerais e critérios básicos para a promoção da acessibilidade das pessoas portadoras de deficiência ou com mobilidade reduzida. Diário Oficial [da] República Federativa do Brasil. Brasília, DF, 19 dez. 2000.

BRASIL. Lei n 10.741, de 1 de outubro de 2003. Instituiu o Estatuto do Idoso. Diário Oficial [da] República Federativa do Brasil. Brasília, DF, 1 out. 2003. Disponível em: <http:// www.planalto.gov.br/ccivil_03/leis/2003/l10.741.htm>. Acesso em: 13 ago. 2013.

BRASIL. Lei n 9.985, de 18 de julho de 2000. Institui o Sistema Nacional de Unidades de Conservação da Natureza - SNUC. Diário Oficial [da] República Federativa do Brasil. Brasília, DF, 18 jul. 2000. Disponível em: < http://www.planalto.gov.br/ccivil_03/leis/l9985. htm>. Acesso em: 13 ago. 2013.

BRITO, Maria Cecília Wey de. Unidades de conservação: intenções e resultados. São Paulo: Annablume: FAFESP, 2000.

CORAZZA, Maria Alice. Terceira idade e atividade física. São Paulo: Phorte Editora, 2001.

COSTA, Patrícia Côrtes. Unidades de Conservação: matéria-prima do ecoturismo. Série Turismo. São Paulo: Aleph, 2002.

DOUROJEANNI, M. J.; PÁDUA, M. T. J. Biodiversidade a hora decisiva. 2. ed. Curitiba: UFPR, 2007.

GOVERNO DO PARANÁ. Plano de Manejo: Encarte III - Análise do Parque Estadual Lago Azul. Curitiba: IAP/DIBAP, 2005. Disponível em: <http://www.iap.pr.gov.br/arquivos/File/Plano_de_ Manejo/Parque_Estadual_Lago_Azul/5_PELA_ENCARTE_III.pdf >. Acesso em: 10 abr. 2013. 
MAGNANINI, Alceo. Política sobre as unidades de conservação: dificuldades e sucessos no pensamento de Alceo Magnanini. In: Unidades de conservação: atualidades e tendências. Organizador Miguel Serediuk Milano. Curitiba: Fundação O Boticário de Proteção à Natureza, 2002.

MARCELLINO, Nelson Carvalho. Lazer e humanização. Campinas, SP: Papirus, 1983. Coleção Fazer/Lazer.

MARCONI, Marina de Andrade; LAKATOS, Eva Maria. Técnicas de pesquisa: planejamento execução de pesquisas, amostragens e técnicas de pesquisa. 3. ed. São Paulo: Atlas, 1996.

MELO, Victor Andrade de. Lazer e minorias sociais. São Paulo: IBRASA, 2003.

PARKER, Stanley. A sociologia do lazer. Tradução de Heloisa Toller Gomes. Rio de Janeiro: Zahar, 1978.

PIRES, Paulo dos Santos. Dimensões do ecoturismo. São Paulo: Editora SENAC São Paulo, 2002.

RICHARDSON, Roberto Jarry et al. Pesquisa social: métodos e técnicas. São Paulo: Atlas, 1985.

ROCKTAESCHEL, Benita Maria Monteiro Mueller. Terceirização em áreas protegidas: estímulo ao ecoturismo no Brasil. São Paulo: Editora SENAC São Paulo, 2006.

SASSAKI, Romeu Kazumi. Inclusão: construindo uma sociedade para todos. 7. ed. Rio de Janeiro: WVA, 1997. 